\title{
Influence of Slurried Silica Fume and Water Content on the Microstructure and Diffusion Parameters of Cement Pastes
}

\author{
Z. Bajja*1a,2a , W. Dridii ${ }^{1 b}$, A. Darquennes ${ }^{2 b}$, R. Bennacer ${ }^{2 c}$, P. Le Bescop ${ }^{1 c}$ \\ ${ }^{1} C E A, D E N, D P C, S E C R$, Laboratoire d'Etude du Comportement des Bétons et des Argiles, F-91191 Gif- \\ sur-Yvette, France \\ ${ }^{2}$ LMT-Cachan/ENS-Cachan/CNRS/Université Paris Saclay, 61, Avenue du Président Wilson, 94235 \\ Cachan, France. \\ ${ }^{1 a, b}$ Email :zineb.bajja@cea.fr, ${ }^{1 b}$ Email wissem.dridi@cea.fr, ${ }^{2 a}$ Email aveline.darquennes@cea.fr, \\ ${ }^{2 b}$ Email <rachid.bennacer@ens-cachan.fr>, ${ }^{1 c}$ Email <patrick.le-bescop@cea.fr>.
}

\begin{abstract}
Durability of silica fume cement based materials is of great importance for radioactive waste storage. This study investigates the durability in the aspect of tritiated water (HTO) diffusion in relation with the porosity and the microstructure within silica fume cement pastes. A silica fume (SF) replacement varying from 0 to $20 \%$ by weight of cement was used to prepare cement pastes at water-to-binder ratios (w/b) ranging from 0.3 to 0.5 . The manufactured pastes were tested by through-out diffusion and their microstructure characterized by water and mercury porosimetry (MIP), thermogravimetric analysis (TGA) and by scanning electron microscopy (SEM) associated to (EDS) analysis.

It was observed that the addition of silica fume as a slurry -a liquid mixture of undensified powder and water- offers a better dispersion and improves diffusion properties of SF pastes compared to the use of a densified powder, often studied in literature.

Test results also showed that despite an increase in total porosity, the addition of silica fume has a positive impact on pore refinement and on reducing the effective diffusion coefficients.

Finally, HTO diffusion coefficients seem to increase linearly with w/b ratio especially for Portland cement pastes where the increase is more important compared to SF pastes.
\end{abstract}

\section{INTRODUCTION}

The study of the long-term behavior of cementitious materials remains a topic that arouses the interest of many scientists because of the use of these materials in diverse structures. In particular, cement-based materials are largely used in the nuclear industry either for the construction of nuclear power plants and infrastructure dedicated to radioactive waste storage and disposal. Their good compatibility with various kinds of solid and liquid wastes, their long-term durability, and radionuclides retention capacity make these materials essential for waste conditioning, for containers, and for the elaboration of disposal engineered barriers [Glasser and Atkins 1994; Wilding 1992]. Particularly, formulations manufactured from Portland cement and silica fume (SF) could widely be used as structural elements for surface interim storage. 
Therefore, transport properties of these materials have to be studied in strong relationship with material microstructural features (porosity, pore size), in order to enable more effective prediction of structures service life.

Silica fume (SF) is a by-product of the manufacture of silicon or of various silicon alloys [Malhotra et al. 1987]. It is the result of reduction of quartz with coal, the two major components of the burden, in a submerged electric arc furnace. Silica fume, which contains more than $80-85 \%$ of silica $\mathrm{SiO}_{2}$ in amorphous form, is suitable to use in the cement and concrete industries [Swamy 1986]. It is generally known as a very fine powder whose typical particle size is around $0.1-0.5 \mu \mathrm{m}$ and nitrogen BET surface about $20.000 \mathrm{~m}^{2} / \mathrm{kg}$ [Bye 1999]. It is being used increasingly in the world as a mineral admixture to produce high-performance concrete (HPC) [Bentz and Stutzman 1994].

As the Portland cement begins to react chemically, it releases calcium hydroxide or portlandite (CH). Silica fume reacts with this portlandite to produce pozzolanic calcium silicate hydrates, less porous and denser than the conventional C-S-H formed from Portland cement hydration [Baroughel-Bouny 1998]. Therefore, the amount of hydrates increases, which both increases the strength and reduces the permeability by densifying the matrix of the concrete [Diamond 1986]. Besides this pozzolanic effect, silica fume can also act as filler due to its fineness and because of which, it fits into the porosity of the material [Hewlett 2004].

However, undensified silica fume is rarely used as a Supplementary Cementing Material (SCM) due to its fineness and its low density, which may cause difficulty in transporting and handling such fine powder. In order to accommodate some of these problems, commercial suppliers have responded by providing silica fume in various forms to improve the handling and transport properties of the material, such as densified, slurried or pelletized to increase its bulk density [Boddy et al. 2000]. The differences between these forms are related to the shape and size of the particles and do not affect the chemical composition of the material.

In literature, most research work deals with densified silica fume, a powder easier to handle and cheaper to transport than the undensified form but which is composed of agglomerated ultrafine particles with irregular shapes and sizes between $10 \mu \mathrm{m}$ to several millimeters [Diamond et al. 2003] created during the densification process. In previous studies, some researchers pointed out a high degree of silica fume agglomeration in cement pastes or mortars [Nagasaki et al. 1994; Bonen and Diamond 1992; Sanchez de Rojas et al. 1999]. This agglomeration of silica fume can easily reduce its effectiveness on properties of cement paste and mortar, because of the existence of SF particle clusters, which have a larger diameter, a smaller Specific Surface Area (SSA) and a lower pozzolanic reactivity than the unitary grains.

The first objective of the present study is to quantify the loss of performances -mainly in diffusion coefficients and microstructure- due to the presence of SF agglomerates. For that, two different forms of SF were used: the densified and slurried silica fume called respectively (DSF) and (SSF). Slurried silica fume is a liquid mixture composed of undensified powder and water in equal proportions by weight, which promises a better dispersion into the concrete mix and which has rarely been studied in literature.

The second goal is to determine the effect of water-to-binder (cement + SF) ratio and the influence of SF content on tritiated water diffusivity and microstructural proprieties. For this experimental investigation, SSF was selected for SF cement pastes manufacturing because it showed better durability performances.

\section{EXPERIMENTAL INVESTIGATION}

\section{Raw materials:}

Materials used to make cement silica fume pastes were: Ordinary Portland Cement (European grade CEM I 52, $5 \mathrm{~N}$ CE PM-ES-CP2 NF), densified and slurried silica-fume. The latter is composed of 50.1\% by weight of dried silica fume dispersed in water for a total density of 1.382. The DSF is a gray powder (S95 DM) with a density of 2.24 . The two forms of SF are manufactured in the same production plant 
(CONDENSIL in Anglefort, France) and the dried SF used in both types has the same chemical composition. The difference between these two forms lies in particles size dispersion. Table 1 shows the chemical composition of OPC and dried SF used in DSF and SSF.

Table 1. Chemical composition of OPC and dried SF used in SSF and DSF

\begin{tabular}{|c|c|c|}
\hline Properties & Portland cement OPC & Dried silica fume used in DSF and SSF \\
\hline Oxide composition (wt. \%) & & \\
\hline $\mathrm{SiO}_{2}$ & 22.40 & $95 \pm 2$ \\
\hline $\mathrm{CaO}$ & 66.60 & 0.50 \\
\hline $\mathrm{Al}_{2} \mathrm{O}_{3}$ & 2.96 & 0.20 \\
\hline $\mathrm{Fe}_{2} \mathrm{O}_{3}$ & 2.33 & 0.40 \\
\hline $\mathrm{SO}_{3}$ & 2.13 & 0.10 \\
\hline $\mathrm{MgO}$ & 0.95 & 0.30 \\
\hline $\mathrm{K}_{2} \mathrm{O}$ & 0.15 & 0.10 \\
\hline $\mathrm{Na}_{2} \mathrm{O}$ & 0.10 & 0.60 \\
\hline Loss on ignition $(\%)$ & 1 & 2.5 \\
\hline Density $\left(\mathrm{kg} / \mathrm{m}^{3}\right)$ & 3.16 & 2.24 \\
\hline
\end{tabular}

The particles size distribution of SSF and DSF was measured by laser granulometry without using ultrasonic treatment to have the real particle size of materials introduced during SF cement pastes mixing and not to break any agglomerates of SF if they exist in the measurement device. The parameter of SF particles fineness has an important impact on the pozzolanic activity of silica fume and is responsible for the high water demand. Moreover, fine particles are able to fill the voids created by free water in the matrix [Penjehpour et al. 2011] and thanks to this filler packing effect, SF refines the microstructure of concrete, thereby creating a much denser pore structure [Siddique 2011]. These results will be proved in the first part of "Results and discussion" session where the effect of a good SF dispersion on the porosity and diffusion coefficient will be shown.

Figure 1 shows the particle size distribution of SSF $\left(d_{50}=5 \mu \mathrm{m}\right)$ and DSF $\left(d_{50}=60 \mu \mathrm{m}\right)$.

The diameter of the majority (> 80\%) of SSF particles is less than $10 \mu \mathrm{m}$ whereas the DSF contains agglomerates of size up to $800 \mu \mathrm{m}$.

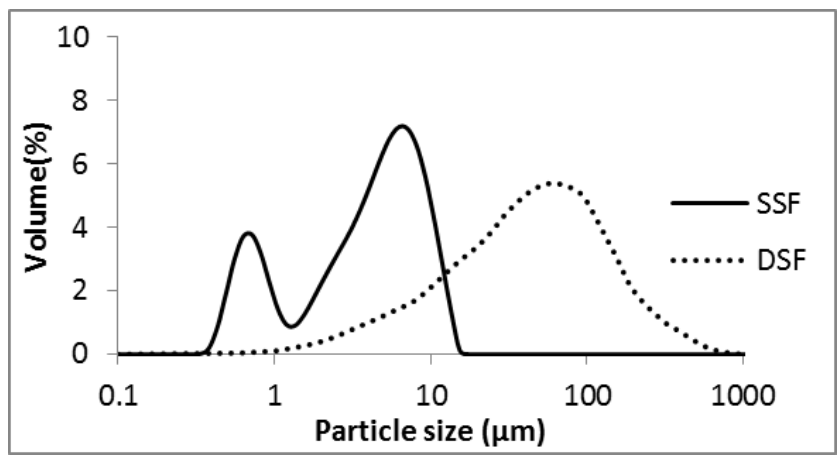

Figure 1. Particle size distributions of slurried silica fume (SSF) and densified silica fume (DSF) 
A superplasticizer called (Glenium27) was used in some formulations of pastes with low water-to-binder ratio in order to improve workability. Water from the slurried silica fume and the superplasticizer was included in the specified $\mathrm{w} / \mathrm{b}$ (ratio of water-to-binder mass).

\section{Sample preparation and conservation}

In this work, six pastes were manufactured. The water-to-binder ratio was varied from 0.3 to 0.5 and silica fume content from 0 to $20 \%$. All pastes were made with slurried SF (except one) because it was proved that slurry is better adapted for sustainability improvement (see next session). Before use, the slurried silica fume was stirred thoroughly with a homogenizer Ultra-Turrax T65D in order to ensure uniformity and to avoid segregation of SF particles inside this liquid mixture. A superplasticizer called (Glenium27) was used in a small amount of $0.2 \%$-by weight of binder (cement $+\mathrm{SF}$ ) - for pastes with low water-to-binder ratio (0.3), in order to improve workability. Water from the slurried silica fume and the superplasticizer was included in the specified $\mathrm{w} / \mathrm{b}$ (ratio of water-to-binder mass). Table 2 summarizes samples proportions.

Table 2. Mixture proportions of SF cement pastes

\begin{tabular}{|c|c|c|c|c|}
\hline Mixture ID & $\begin{array}{c}\text { Water/binder } \\
\text { (mass ratio) }\end{array}$ & $\begin{array}{c}\text { SF replacement } \\
\text { (\% weight of cement) }\end{array}$ & SF form & $\begin{array}{c}\text { Glenium } \\
\text { (\%weight of cement) }\end{array}$ \\
\hline P-10-0.3-D & 0.3 & 10 & Densified & $0.2 \%$ \\
\hline P-10-0.3 & 0.3 & 10 & Slurry & $0.2 \%$ \\
\hline P-10-0.4 & 0.4 & 10 & Slurry & -- \\
\hline P-10-0.5 & 0.5 & 10 & Slurry & -- \\
\hline P-20-0.4 & 0.4 & 20 & Slurry & -- \\
\hline P-0-0.4 & 0.4 & 0 & Slurry & -- \\
\hline
\end{tabular}

Mixtures preparation was based on the standard fabrication procedure NF EN 196-1. Cylindrical samples $(7 \varnothing \times 11 \mathrm{~cm})$ were cast and compacted using a vibrating table in order to evacuate air bubbles. The molds with fresh mortars are sealed with plugs to avoid evaporation for the first 24 hours. Then, samples are demolded and immersed in a saturated lime solution for 6-month period at $20 \pm 1^{\circ} \mathrm{C}$.

After the curing period, the samples were sectioned from the center to produce $6 \mathrm{~mm}$ thick discs. One disc was used for diffusion tests and the others for microstructure characterization.

\section{Tritiated water diffusion measurements}

Samples were tested by the through-out diffusion method. It consists on putting a sample disc between two compartments. The samples were sealed into position using an "Araldite®" epoxy adhesive and by means of O-rings to avoid leakage. The downstream compartment is filled with an alkaline solution $(\mathrm{NaOH}=0.1$ $\mathrm{mol} / \mathrm{L} ; \mathrm{KOH}=0.1 \mathrm{~mol} / \mathrm{L} ; \mathrm{CaO}=2 \mathrm{mmol} / \mathrm{L}$ ) in order to prevent cement pore solution from leaching. The same alkaline solution doped with radioactive tritium water (HTO) was incorporated in the upstream compartment. At the beginning, the upstream concentration $\mathrm{C}_{0}$ is equal to $510^{6} \mathrm{~Bq} / \mathrm{L}$ and downstream one $\mathrm{C}_{1}$ was set to zero. The concentration of tritiated water in the downstream compartment was followed over time until the steady state has been reached. By adjusting experimental and analytical curves based on the resolution of fick's laws, the effective diffusion coefficient $\mathrm{D}_{\mathrm{e}}$ can be obtained. 


\section{RESULTS AND DISCUSSION}

\section{Effect of SF dispersion}

Two pastes were manufactured with densified silica fume (P-10-0.3-DSF) and SSF (P-10-0.3) for the same $\mathrm{w} / \mathrm{b}$ ratio of 0.3 . After 6 -months-curing period, samples were tested by through-out diffusion tests using HTO to determine their effective diffusion coefficient $\mathrm{D}_{\mathrm{e}}{ }^{\mathrm{HTO}}$ of each paste. The microstructure was characterized by water porosimetry, ThermoGravimetry Analysis (TGA) and Scanning Electronic Microscope (SEM) associated to (EDS). The latter gives an idea about the dispersion of microsilica inside cement pastes. Figure 2 represents the EDS mapping of silicon and calcium concentrations. Silica and calcium present in the cement pastes are shown respectively in white and black.
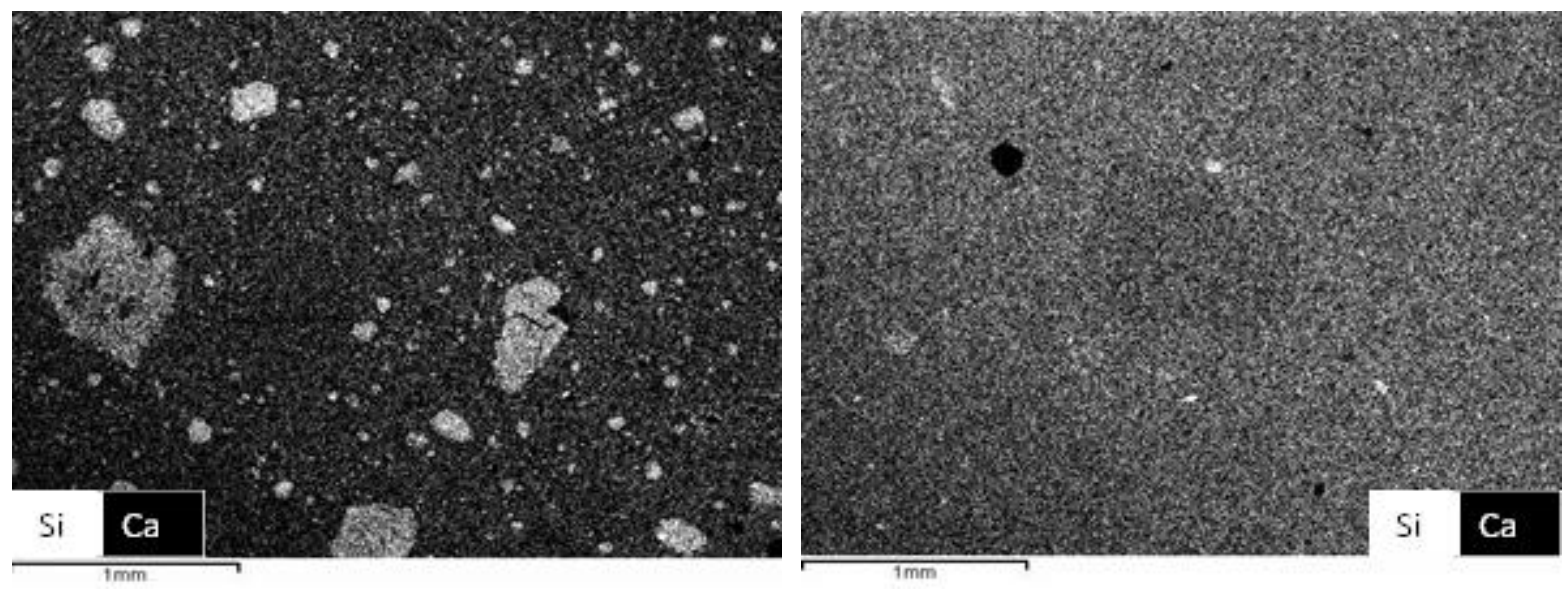

Figure 2. Silicon and calcium mapping of SF cement paste manufactured with DSF (on the right) and with slurry (on the left).

At the same observation scale for both samples, the cement paste made with densified silica fume (Fig 2 on the right) shows the presence of several silica agglomerates with irregular shapes and sizes between 10 and several hundred micrometers $(\mu \mathrm{m})$. The silica $\left(\mathrm{SiO}_{2}\right)$ was verified by the existence of Oxygen and Silicon and the absence of Calcium.

On the other side, the cementitious matrix of the paste P-10-0.3 manufactured with slurry (silica fume in a liquid suspension) seems to be more homogeneous and the SF well dispersed.

The effect of SF dispersion can be viewed in some parameters and not in others. For example, regarding water porosimetry, the free water porosity obtained for the P-10-0.3D paste and the P-10-0.3 are equal (around $24.1 \%$ ). Water porosity is thus a general parameter that estimates the total pore volume but which is not very sensitive to changes in fine porosity. Fortunately, other techniques are able to detect this inhomogeneous dispersion of SF, such as the TGA or the liquid diffusion (in this case the diffusion of tritiated water HTO).

Thermogravimetric analysis (TGA) was used to quantify the portlandite by mass loss between 400 and $600^{\circ}$ [Ramachandran et al. 2002; Villain et al. 2007]. Portlandite content helps given an idea about the effectiveness of the SF pozzolanic reaction. Table 3 shows the values of portlandite content and effective diffusion coefficients obtained for each paste. 
Table 3. Portlandite content and effective diffusion coefficient obtained for SF cement pastes made with DSF and SSF

\begin{tabular}{|l|c|c|}
\hline & P-10-0.3D & P-10-0.3 \\
\hline CH content $(\mathrm{g} / \mathrm{g}$ of binder) & $16.24 \%$ & $14.66 \%$ \\
\hline Effective diffusion coefficients $\mathrm{D}_{\mathrm{e}}{ }^{\mathrm{HTO}}\left(\mathrm{m}^{2} / \mathrm{s}\right)$ & $6.410^{-13}$ & $2.6710^{-13}$ \\
\hline
\end{tabular}

Portlandite content is lower in SF cement paste made with slurry. This is probably due to the better dispersion of SF inside the cementitious matrix and thus a higher pozzolanic reactivity of the unitary particles compared to SF clusters which have a larger size and a smaller reactive surface.

The poor SF dispersion or the presence of agglomerates doubles the effective diffusion coefficient and decreases SF efficiency. In literature, many techniques have been suggested to improve particle dispersion such as sonication treatment [Rodriguez 2012] or hydrodynamic shear [Bohin et al. 1996] amongst others. Such techniques improve SF dispersion but are quite laborious and difficult to be applied before each material preparation.

The slurry -a mixture ready to use- must then be favored for an optimal SF dispersion and for a higher gain on diffusion coefficients. All samples cited thereafter have been manufactured with slurry to provide a better sustainability.

\section{Effect of SF content}

Silica fume content was varied between 0,10 and $20 \%$ for cement pastes having the same initial porosity. Silica fume cement pastes concerned are P-0-0.4; P-10-0.4; P-20-0.4.

Figure 3 shows the water porosity values for each tested paste after 6-months curing period. Average relative error doesn't exceed $3 \%$.

It is noticed that the total porosity increases linearly with SF addition. This increase is probably due to SF which consumes the portlandite $(\mathrm{CH})$-non porous- to produce porous hydrates $\mathrm{C}-\mathrm{S}-\mathrm{H}$.

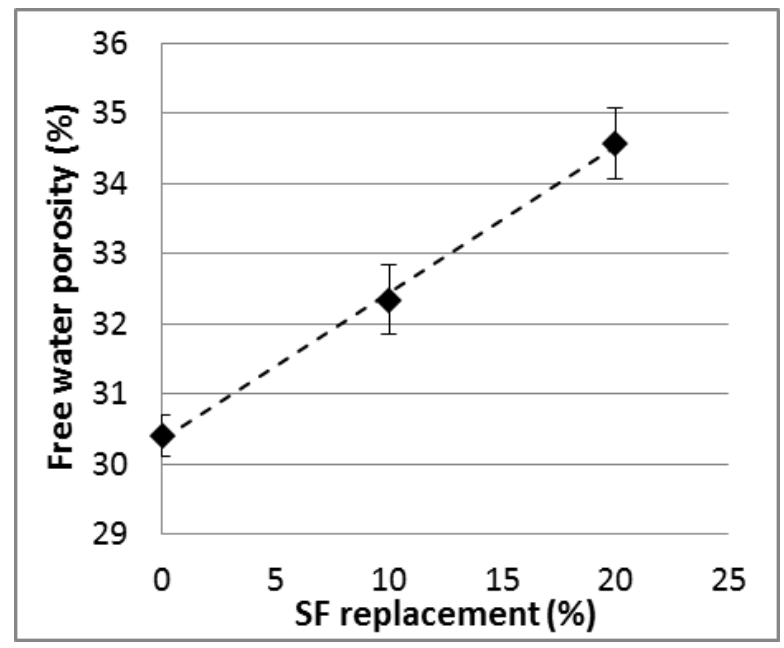

Figure 3. Water porosities for pastes with different SF replacement

At first sight, this result may mean that the addition of SF has a negative effect on the microstructure of the material since it increases the total pores volume. However, water porosity remains a macroscopic 
parameter that does not give more information or details about the microstructure and pores structure. Other techniques such as mercury porosimetry can provide more information on pore size distribution despite its limits with pore access diameter $>3 \mathrm{~nm}$. Figure 4 shows pore size distribution with increasing SF content.

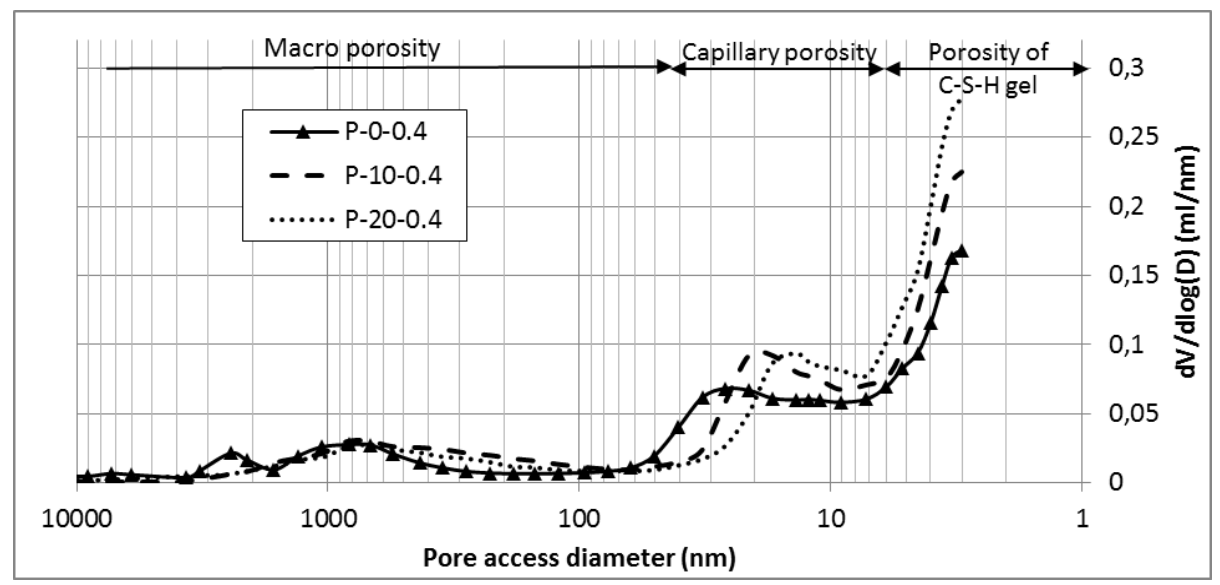

Figure 4. Effect of SF addition on pore size distribution

It is considered that pores of $6 \mathrm{~nm}$ or less in diameter correspond to gel pores that mainly exist in precipitated $\mathrm{C}-\mathrm{S}-\mathrm{H}$ structures. Pores between 6 to $50 \mathrm{~nm}$ in diameter correspond to capillary pores formed in hydrates, and those of $50 \mathrm{~nm}$ or larger correspond to large-diameter capillary pores and to macro porosity [Uchikawa et al. 1996].

First, the addition of SF in a cementitious mixture increases the C-S-H content (area with pore access diameter $<6 \mathrm{~nm}$ ). This increase finds its origin in the pozzolanic reaction which produces more pozzolanic $\mathrm{C}-\mathrm{S}-\mathrm{H}$ as more silica is available. This result is fully in line with the values of portlandite content obtained by TGA. Table 4 represents the amount of portlandite $(\mathrm{CH})$ in each silica fume cement paste.

Table 4. Effect of SF addition on portlandite content

\begin{tabular}{|l|c|c|c|}
\hline Mixture ID & P-0-0.4 & P-10-0.4 & P-20-0.4 \\
\hline CH content (g/g of binder) & $29.0 \%$ & $19.6 \%$ & $18.6 \%$ \\
\hline
\end{tabular}

Therefore, it is found that adding SF in cementitious mixture consumes portlandite in order to produce more pozzolanic C-S-H. The $\mathrm{CH}$ consumption is more important (around $0.1 \mathrm{~g} / \mathrm{g}$ binder) with the addition of $10 \%$ of SF, and does not change a lot with $20 \%$ SF adding $(0.11 \mathrm{~g} / \mathrm{g}$ of binder). The effectiveness of SF pozzolanic reactivity decreases after $10 \% \mathrm{SF}$ addition.

Coming back to mercury porosimetry curves (figure 4), a refinement of capillary porosity is observed with the addition of SF, in other words, the capillary critical pore radius $\left(r_{c}\right)$-corresponding to the radius at the peak of capillary porosity- is thinner for silica fume cement paste with $20 \% \mathrm{SF}$ adding. This refinement of the capillary porosity is probably due to the "filler" effect of SF particles which fill into the porous space and accordingly explain narrow pores observed in these materials with SF adding. In our case, the critical radius of the capillary pores is equal to 15,10 and $8 \mathrm{~nm}(30,20$ and $16 \mathrm{~nm}$ in pore diameter) respectively for SF cement pastes with 0, 10 and $20 \%$ of SF addition.

The fineness of capillary pores has a direct impact on the liquid diffusion. Figure 5 shows the effective diffusion coefficients of tritiated water (HTO) as a function of the critical pore radius. 


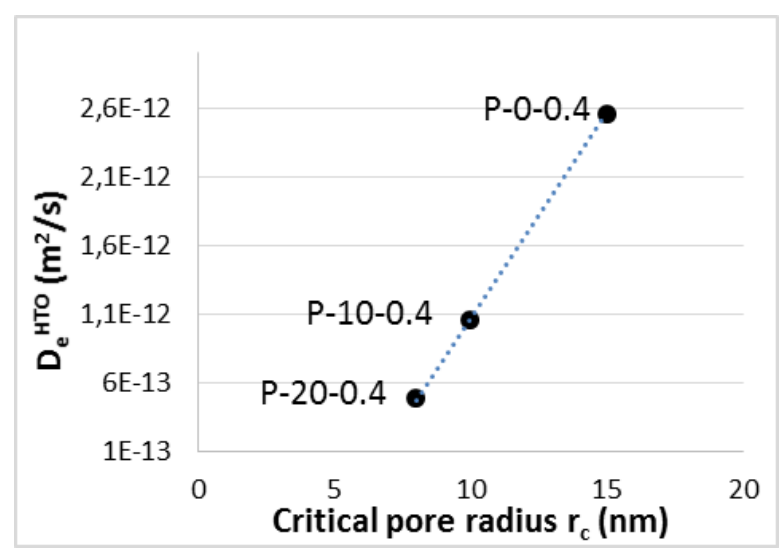

Figure 5. Effective diffusion coefficients with SF addition

The diffusion coefficient of HTO increases linearly with the capillary critical pore radius. A similar linearity was also observed by [Halamickova et al. 1995] using chloride diffusion.

\section{Effect of water-to-binder ratio}

Water-to-binder ratio was varied from $0.3,0.4$ and 0.5 for silica fume cement pastes with $10 \%$ SF replacement. Table 5 summarizes water porosity values for each tested paste.

Table 5. Water porosities with different $\mathrm{w} / \mathrm{b}$ ratios

\begin{tabular}{|c|c|c|c|}
\hline Mixtures ID & P-10-0.3 & P-10-0.4 & P-10-0.5 \\
\hline Free water porosity (\%) & $24.1 \pm 0.3$ & $32.2 \pm 0.5$ & $39.6 \pm 0.5$ \\
\hline
\end{tabular}

As expected, porosity values increase linearly with the addition of water. This raise in porosity affects both capillary and hydrates porosity (respectively micro and nano porosity). Figure 6 represents the distribution of the pore volumes as a function of pore access diameter.

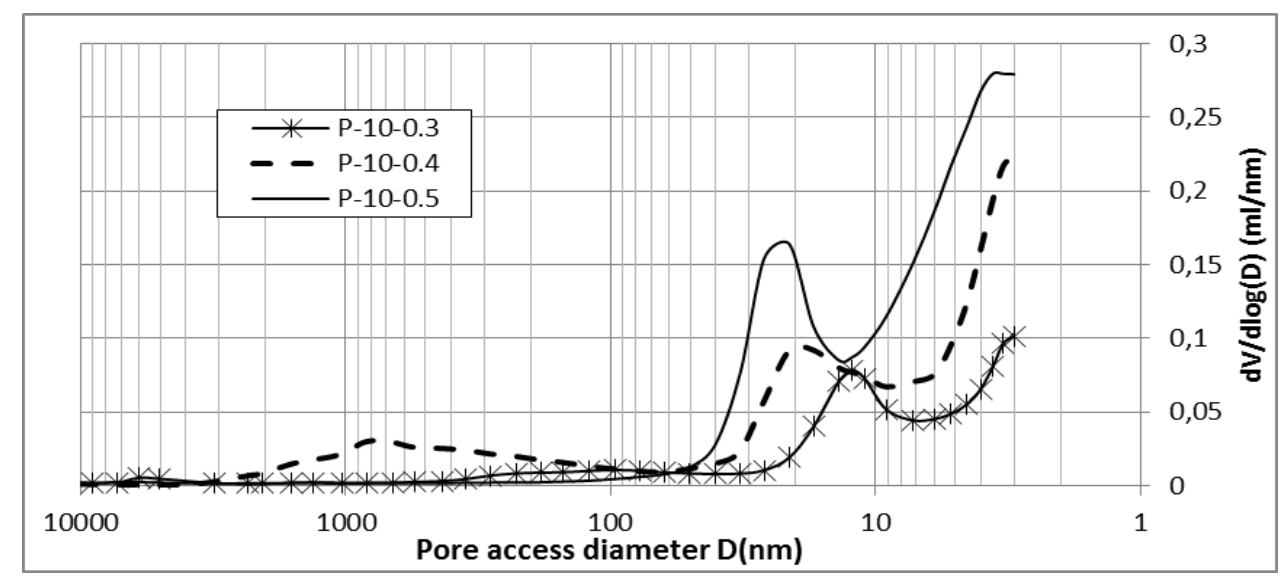

Figure 6. Effect of w/b ratio on pores size distribution of cement pastes with $10 \% \mathrm{SF}$ content 
As w/b ratio increases, the material is better hydrated favoring thereby the formation of more C-S-H. Also, the addition of water makes more capillary pores with a larger critical radius $\left(r_{c}\right)$. The latter increases from 6,10 and $11 \mathrm{~nm}$ (equal to 12,20, and $22 \mathrm{~nm}$ in diameter) respectively for a w/b ratio of $0.3,0.4$ and 0.5 . As a consequence of critical radius widening, the effective diffusion coefficients increase -here also-. Figure 7 represents the effective diffusion coefficients as a function of $\mathrm{w} / \mathrm{b}$ ratio. This figure compares the values of $\mathrm{D}_{\mathrm{e}}$ obtained for silica fume cement pastes with $10 \%$ SF addition and the diffusion coefficient values of cement pastes made without SF -collected from a previous study [Larbi 2013]-.

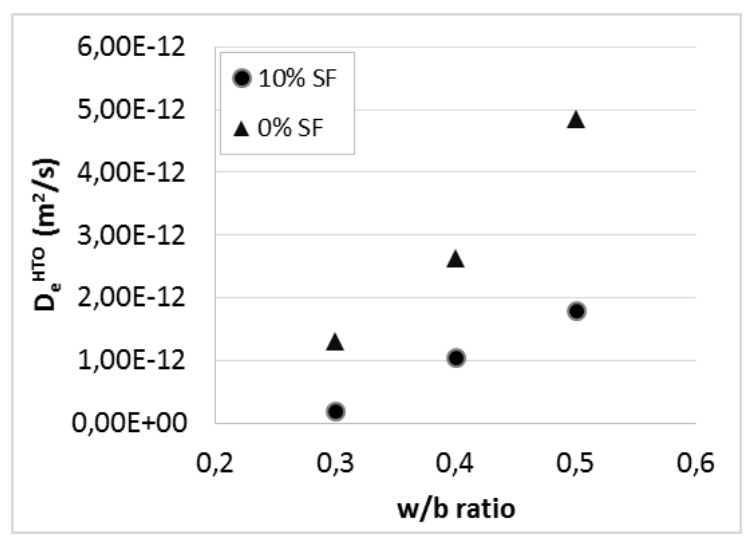

\section{Figure 7. Effective diffusion coefficient for cement with and without SF addition}

The increase of the critical radius noticed for cement pastes with and without SF addition, can explain the rise of the diffusion coefficient with w/b ratios.

However, the diffusion coefficients don't raise in the same way i.e. for cement pastes without SF, the slope is steeper which means -in other words- that diffusion increases more dramatically with w/b ratio if no SF was added. Thus, the presence of SF in cementitious mixtures reduces the impact of water addition and makes materials more resistant to the penetration of diffusive elements such as HTO molecules.

\section{CONCLUSION}

As a conclusion, this study provides many important results summarized hereafter:

- The use of silica fume as a slurry offers a better dispersion of silica inside the cementitious matrix and improves diffusion properties: the diffusion coefficient is reduced by half compared to a cement paste made with the densified form of SF promoting the agglomeration of SF particles.

- The addition of SF increases the total porosity but refines pores by reducing their size. Accordingly, the diffusion coefficient decreases significantly.

- HTO diffusion coefficients increases linearly with w/b ratio especially for Portland cement pastes where the increase is more important compared to SF pastes. The presence of SF in cementitious mixtures reduces the impact of water addition and makes the penetration of HTO in microsilica pastes demonstrably slower than comparable normal pastes.

\section{ACKNOWLEDGMENTS}

The authors gratefully acknowledge the financial support from CEA and Electricité De France (EDF).

\section{REFERENCES}


Baroughel-Bouny V. (1998). "Texture and moisture properties of ordinary and high-performance cementitious materials", Proc. Of the International RILEM Conference Concrete: from Material to Structure, pp. 144-165.

Bentz D.P., Stutzman P.E. (1994). "Evolution of porosity and calcium hydroxide in laboratory concretes containing silica fume", Cem. Concr.Res. 24, pp. 1044- 1050.

Boddy A.M., Hooton R.D., Thomas M.D.A. (2000). "The effect of product form of silica fume on its ability to control alkali - silica reaction", Cem.Concr. Res. 30, pp. 1139-1150.

Bohin F., Ica Manas-Zloczower, Donald L. Feke (1996). "Kinetics of dispersion for sparse agglomerates in simple shear flows: Application to silica agglomerates in silicone polymers". Chemical Engineering Science. Volume 51, Issue 23, pp. 5193-5204.

Bonen D., Diamond S. (1992). "Occurrence of large silica fume-derived particles in hydrated cement paste", Cem. Concr. Res. 22, pp. 1059- 1066.

Bye G.C. (1999). "Portland Cement, 2nd ed.", Thomas Telford, London.

Diamond S. (1986). "The microstructures of cement paste in concrete". In: Proceedings of the 8th International Congress on Chemistry of Cement, Rio de Janeiro, vol. 1, pp. 122-147.

Diamond S., Sahub S., Thaulowb N. (2003). "Reaction products of densified silica fume agglomerates in concrete", Cem. Concr.Res. Volume 33, Issue 10, pp. 1543-1548.

Glasser, F.P., Atkins, M., (1994). "Cements in radioactive waste disposal” MRS Bull, pp. 33-38.

Wilding C.R., (1992) "The performance of cement based systems" Cem. Concr. Res., 22 (2), pp. 299310.

Halamickova P., Bentz D.P., Garboczi E.J., Detwiler R.J. (1995). "Water permeability and chloride ion diffusion in portland cement mortars: Relationship to sand content and critical pore diameter", Cem. Concr. Res. 25 (4), pp. 790-802.

Hewlett P.C. (2004). "Lea's Chemistry of Cement and Concrete" (Fourth Edition).

Larbi B. (2013) "Caractérisation du transport diffusif dans les matériaux cimentaires: Influence de la microstructure des mortiers", thesis in French.

Malhotra V.M., Ramachandran V.S., Feldman R.F., Aitcin P.C. (1987). "Condensed Silica Fume in Concrete", CRC Press, Boca Raton, FL.

Nagataki S., Otsuki N., Hisada M. (1994). "Effects of physical and chemical treatments of silica fume on the strength and microstructures of mortar", High-Performance Concrete, Proceedings of ACI International Conference, Singapore, American Concrete Institute, Detroit, MI, pp. 21-35.

Panjehpour M., Abdullah Abang Ali A., Demirboga R. (2011). "A review for characterization of silica fume and its effects on concrete properties", Int. J. Sustainable Constr. Eng. Technol. 2 (2).

Ramachandran V.S., Ralph M.P., Baudoin J.J., Delgado A.H. (2002). "Handbook of Thermal Analysis of Construction Materials", Noyes Publications.

Rodríguez E.D., Lourdes Soriano, Jordi Payá, María Victoria Borrachero, José M. Monzó (2012). "Increase of the reactivity of densified silica fume by sonication treatment". Ultrasonics sonochemistry, 19 pp. 1099-1107

Sanchez de Rojas M.I., Rivera J., Frias M. (1999). "Influence of the microsilica State on pozzolanic reaction rate". Cem. Concr. Res. 29(6), pp. 945-949.

Siddique R. (2011). "Utilization of silica fume in concrete: review of hardened properties", Resour. Conserv. Recycl. 55, p. 923-932.

Swamy R.N. (1986). "Cement Replacement Materials", Surrey University Press, Blackir and Son, London.

Uchikawa H., Hanehara S., Hiaro H. (1996). "Influence of microstructure on the physical properties of concrete prepared by substituting mineral powder for part of fine aggregate". Cem. Concr. Res. 26 (1), pp. 101-111.

Villain G., Thiery M., Platret G. (2007). "Measurement methods of carbonation profiles in concrete: Thermogravimetry, chemical analysis and gammadensimetry", Cem. Concr. Res. 37, pp. 1182-1192. 